\title{
Milliliter per Minute per Millimeters of Mercury
}

National Cancer Institute

\section{Source}

National Cancer Institute. Milliliter per Minute per Millimeters of Mercury. NCI Thesaurus.

Code C67417.

A unit for measuring a pulmonary diffusing capacity expressed in units of gas flow rate (in milliliters per minute) per a unit of pressure (in torrs). 